\title{
Professional Engineering in California
}

\author{
R. W. SOR E N S N \\ FELLOW AIEE
}

$\coprod$ foll N THE MAGAZINE Newsweek for June 11, 1951, the following comment from a reader was published:

Engineer Shortage: An item in Newsweek May 21 (Business Trends) says that there is a shortage of "engineers." This problem could be easily licked. There is not much to the average American "engineer" anyway. A good shop foreman or machinist could be trained in a few weeks to do everything that most engineers do. The mass-produced American "engineer" is not a creative type like Gottlieb Daimler or Rudolf Diesel. In fact, he is coming to be noted far and wide for the jejune sterility of his mind. His overbloated reputation is due merely to educational snobbery and educational racketeering, coupled with the "caste consciousness" of too many personnel offices. The problem could be easily solved through a training program in the plants designed to restore a truly American equality of opportunity to our American industrial system.

Obviously, the fact that Newsweek will give space to such words indicates that Professional Engineers must develop some means to raise the general knowledge status of what constitutes Professional Engineering. Other reasons for raising the status might include: a present substandard professional criteria; an aim for perfection; too many substandard registered professional engineers; a demand for more engineers that can keep pace with our expanding knowledge of nature's laws; an acceleration of time-saving inventions; a need for an income that will better provide for self and family; and a deficiency of a code of ethics, inspiring leaders, engineers of culture, interest in community welfare, and devotion to the moral and spiritual elements of living.

With these items in mind, the author, AIEE representative on the California Board of Registration for Professional Engineers, presents an account of his stewardship. It is his duty to study the applications and examinations of all electrical engineers who desire registration and to present the results of that study to the Board in order that it may determine the right of each one for registration. A large majority of the present registered electrical, mechanical, chemical, and petroleum engineers were registered under the 1947 grandfather clause. ${ }^{*}$ The recommendations to the Board for such men were not alone those of the author, for he had the help of a number of committees selected from the AIEE membership who supplied information to the Board as requested. No doubt some errors were made. Perhaps a very few qualified men were denied registration without the written examination. Also, no doubt a much

*The grandfather clause grants boards of registration the right to register without the regular examination engineers who, in the opinion of the board, have shown evidence of being qualified by education and practice to pass a board examination. The clause is used only when a registration act is first passed and it contains a time limit. larger number who would have failed a written examination and were largely specialists in limited fields to which they will confine their activities, were registered. Their lack of up-to-date broad engineering experience will not cause them to endanger life or property. Nevertheless, some nonregistered persons who think they should be registered tell us how much better they are than some of their registered associates. Those men always have the right to prove by examination their right to be registered.

The only legal basis for registration is the protection of life and property. With that in mind, the present status of registration in California is indicated by Tables I, II, and III.

Table I. California Professional Engineers Registered Under the Grandfather Clause

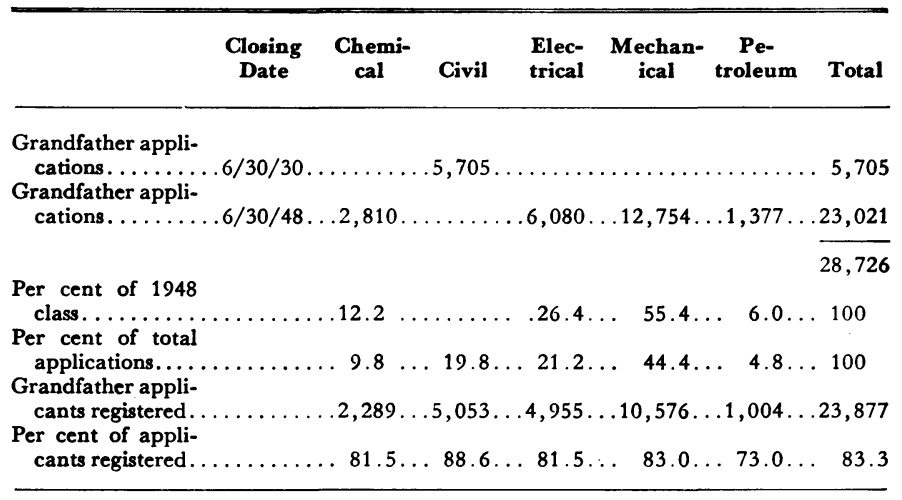

It is interesting to note that 63 per cent of the engineers registered under the grandfather clause were college graduates and 37 per cent not college graduates, but only one-third of the noncollege graduates had no formal school attendance beyond high school.

Table II. Withdrawals and Number of Expected Applicants

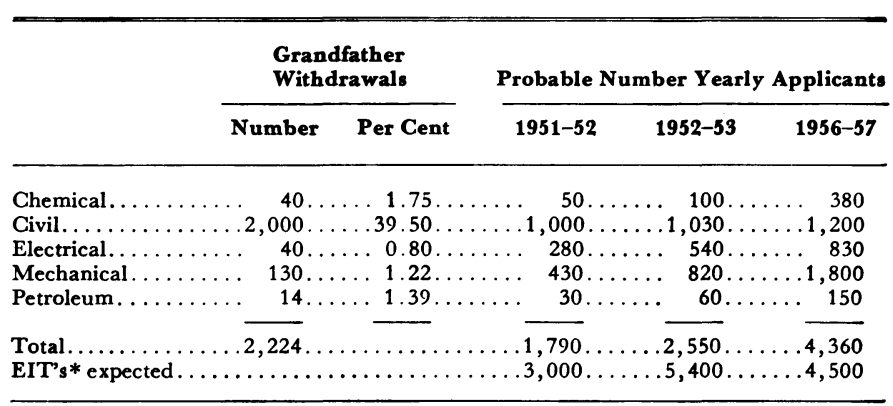

* "Engineers in Training" are men who can pass the first half of the 2-day examinations but who have not had 6 years of acceptable experience.

Revised text of an address, "Raising the Status of the Professional Engineer," presented before the AIEE Los Angeles Section.

R. W. Sorensen is professor emeritus of electrical engineering, California Institute of Technology, Pasadena, Calif. 
Table III. Candidates Taking Written Examinations and Number of Valid Certificates Since the Five Classes Became Operative

\begin{tabular}{|c|c|c|c|c|c|}
\hline & \multirow[b]{2}{*}{$\begin{array}{l}\text { Taking } \\
\text { Number }\end{array}$} & \multirow{2}{*}{$\frac{\text { Passing }}{\text { Number Per Cent }}$} & \multicolumn{2}{|c|}{ Certificates Valid } & \multirow{2}{*}{$\begin{array}{c}\text { Estimated } \\
\text { Professional } \\
\text { Society } \\
\text { Members }\end{array}$} \\
\hline & & & $6 / 30 / 51$ & $\begin{array}{c}\text { Estimated } \\
6 / 30 / 52\end{array}$ & \\
\hline \multirow[t]{2}{*}{$\begin{array}{l}\text { Chemical. . } \\
\text { Civil. ....... } \\
\text { Electrical. . } \\
\text { Mechanical. } \\
\text { Petroleum. . }\end{array}$} & $\begin{array}{lr}\ldots & 22 \ldots \\
\ldots & 1,279 \ldots \\
\ldots & 118 \ldots \\
\ldots & 185 \ldots \\
\ldots & 19 \ldots \\
& \text { Structura } \\
& \text { Land sur } \\
& \text { EIT. . . }\end{array}$ & 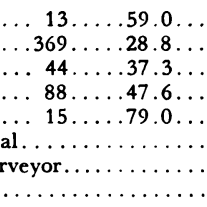 & $\begin{array}{r}2,252 \ldots \\
5,938 \ldots \\
4,910 \ldots \\
10,452 \ldots \\
. \quad 982 \ldots \\
507 \ldots \\
8886 . \\
3,365 \ldots\end{array}$ & $\begin{array}{lr}\ldots & \\
\ldots & 520 \\
\cdots & 910 \\
\ldots & 4,670\end{array}$ & $\begin{array}{l}\ldots \quad 800 * \\
\ldots 2,200 * \\
\ldots 4,000 * \\
\ldots 5,200 * \\
\ldots 2,600 * *\end{array}$ \\
\hline & Total. & & $29,337$. & $\ldots 31,326$ & \\
\hline
\end{tabular}

Registered electrical engineers: college graduates 63 per cent; nongraduates 37 per cent. * Estimated as two times Los Angeles members.

** Includes petroleum, mining, and metallurgical engineers.

In addition to the work indicated by the tables, the Board has the task of handling each year about 500 complaints of law infringement. Each complaint requires considerable investigation. Sometimes the offender when informed by an investigator that he has broken the law arranges to observe all the legal requirements incident to engineering work. All too frequently, however, the Board must file court action.

In popular usage, the word "engineer" has come to include many men who are merely technicians or mechanics. In order to set a professional standard for engineers, many states now have passed registration laws defining the qualifications of a Professional Engineer. This article describes the provisions for registration in the State of California.
We have had good support in

court decisions. Sometimes even in extreme cases where the Board and its members have been accused by persons not certified as being unfair and subjected to mandamus suits the decisions have been favorable for the Board. We have a record of one case in an eastern state where the court ruled that an engineer not registered could not collect payment for his engineering service.

\section{WHAT IS PROFESSIONAL ENGINEERING?}

$\mathrm{W}^{\mathrm{w}}$ HAT is professional engineering? Who has the right to be a professional engineer? There is only one legal answer in California, and the same statement is probably true for every other state in the Union and also for Alaska, Hawaii, Puerto Rico, and Canada; namely, registration with an official Board of Registration, sometimes called a Board of Examiners.

How does one know what is professional engineering and what must be done by persons wishing to qualify as professional engineers? The California Act, Sections 6700 and 6701, reads as follows:

(6700) This chapter of the Business and Professions Code constitutes the chapter on professional engineers in the branches of chemical, civil, electrical, mechanical, and petroleum engineering. It may be cited as the Civil and Professional Engineers Act.

(6701) "Professional engineer," within the meaning and intent of this act, refers to a person engaged in professional practice of rendering service or creative work requiring education, training and experience in engineering and the application of special knowledge of the mathematical, physical and engineering sciences in such professional or creative work as consultation, investigation, evaluation, planning or design of public or private utilities, structures, machines, processes, circuits, buildings, equipment or projects, and supervision of construction for the purpose of securing compliance with specifications and design for any such work.

The Act also defines at considerable length what constitutes Professional and Civil Engineering and tells quite specifically what civil engineers may or may not do. Chemical engineers, electrical engineers, mechanical engineers, and petroleum engineers without registration may not legally use the title Professional Engineer or the other titles just mentioned. Notwithstanding all the definitions of engineering and descriptions of professional engineering set forth in the Act, drawing a sharp line between what is and what is not professional

- engineering is very difficult. California-registered Professional Engineers must be engineers with 6 years of qualifying experience acceptable to the Board and must have a knowledge of the basic fundamentals of science and mathematics upon which engineering is based. Also, evidence of ability to use these fundamentals in engineering must usually include experience in the design of engineering works rather than simply operation experience. One does not consider automobile drivers as automobile engineers. The word "design," of course, is used in its broad sense and not in the sense of being limited as a definition that indicates only making drawings and computations.

Our study of the status of the Professional Engineer does not indicate that the engineering profession is to any considerable degree deficient in proper standards, but no doubt all of us are of one accord in agreeing that the top standard has not been reached. Indeed, if that were so then probably there would be no need for a registration law.

Engineers are aiming toward perfection but when all problems have been solved in the best possible manner there will be no more engineering.

The opening paragraph refers to the public's poor understanding of the meaning of the term "Professional Engineering." Some persons indeed see no difference between an elevator operator and the designer of all of the intricate mechanisms that go into an automatic elevator to provide good and safe operation. We all know that the word "engineer" is probably misused more than any other word unless, perchance, it be the title "Doctor." Physicians have educated the public to distinguish between medical doctors and other types of doctors by the use of the letters M.D. after their names. Perhaps engineers should emphasize a program of using titles such as John Doe, P.E., unless some better name for professional engineering can be developed. 
Raising the status of the Professional Engineer may cause some persons to think engineers should aim definitely to raise their personal incomes. A 1938 AIEE paper $^{1}$ showed that lawyers and doctors, thought by many engineers to be very highly paid, had take-home incomes after the deduction of office and other operating expenses that were in general no better than those of the engineers of equal standing. Conditions for engineers are probably equally favorable at the present time. Certainly if engineers consider themselves entitled to professional standards the salary status should not be raised by group-forced barter but rather should be determined by the demand for engineers known for high efficiency and expert knowledge. Perhaps men doing routine work sometimes called engineering, such as drafting and other subengineering work, should use an organized group barter plan as a last resort.

\section{SUBSTANDARD REGISTERED PROFESSIONAL ENGINEERS}

$\mathrm{P}$ ASSING THE required registration examination in no way determines the grading of engineers but simply furnishes evidence that the registrant meets certain minimum requirements. This is, of course, as it should be. Then comes the question: How "stiff" should the examination be? In California the only way to qualify for registration is by examination. California law has no reciprocal provision which automatically gives registered professional engineers in other states California registration upon application. Establishing and maintaining a standard for these examinations is no easy matter. The men to be examined naturally have practiced in many fields; thus, a fair examination can be only a general one with probably a few options for the benefit of specialists. Also, it should deal to considerable extent with fundamentals considered by many college work. Students are no longer taught that physics courses must be passed and then forgotten.

There are many activities tending to reduce or tear down the rigor of the examination. Some of these are the desire of other State Boards to have their registrants recognized in a reciprocal procedure. If all states gave equally rigorous examinations, that would be ideal. The fact that they do not is probably not due to laxity on the part of the State Boards but rather is due to popular opinion, pressure from not-to-well-qualified persons who want registration, and political expediency factors that legislatures introduce into registration acts. Some state acts are so weak that persons may obtain registration merely by reporting evidence of experience. In some states registration may be obtained simply by graduation from an engineering college. There is the pressure of semiengineers who are good salesmen but carry on only limited engineering activities and think the tone of the examinations should be reduced to a standard suitable to the training of such men. Unfortunately, there are still many older men educated as engineers who now are high-class repairmen, electricians, or technicians of ability but who do not realize that engineering today is not what it was 50 or perhaps even 30 years ago and are thus unable to distinguish between true engineering and technician abilities. Most registration examinations demand a rather high level of engineering experience and ability for passing. There has been some desire for uniform examinations for the entire country. Such examinations of course would have to be the resultant of many opinions and thus certainly would not be the rigorous examination desired by some states but would be compromise examinations. In addition, the mechanics of trying to give throughout the nation a stated examination at one particular date would be difficult. Arranging a common time for only four or five places in one state is often difficult.

There are still many engineers who have been admitted under grandfather clauses which, of course, must not be too restrictive but which in some states have been so lax as to permit practically anyone and everyone so desiring to register as an engineer. Indeed, there are persons in California who declare that such provision was made by the California grandfather clause whereas actually the grandfather clause in California simply gave the Board the right to register without examination men who in their opinion were qualified to pass a registration examination.

Are there too many registered professional engineers? Reference to the tables shows that chemical engineers in California have a professional registration of nearly three times the California membership of the Chemical Engineering Society. The registered civil engineers number $2^{1 / 2}$ times the members of the American Society of Civil Engineers in the state. The electrical engineers have almost an even number of registrants and AIEE members, the number of registrants being 4,900 and the professional society members approximately 4,000. However, there are many registered professional engineers in the electrical engineering field who are not members of the AIEE or the Institute of Radio Engineers. The mechanical engineers have about twice as many registered engineers in California as members of The Society of Mechanical Engineers. No similar statistics are available for petroleum engineers because their membership is in an organization that includes mining and metallurgical engineers. These data indicate that too many engineers are neglecting the opportunities incidental to membership in the professional societies. Perhaps if that were not so and the professional society classifications were rigorously observed the practice of using professional society membership as a gauge of professional ability, which has been advocated by some professions, would be satisfactory. At present, however, there are very little data of value in this respect and there is no legal status as a professional engineer by virtue of membership in professional societies.

Professional engineering is a progressive science demanding that the status of the profession be raised apace with man's ever-expanding knowledge of nature's laws.

Engineers must study continually during their engineering activity to keep pace with the many channels in which engineering has developed. Indeed, it is difficult for specialists to keep up with their own special subdivisions of engineering. The progressiveness of engineering is proved by hundreds of examples. A simple one is induction motor design. A 40-horsepower motor is now made on the same frame that only 10 years ago was considered proper for only 30 horsepower, and 40 years ago that 
frame was used for motors of only 10 horsepower. The power now developed by a frame is four times what was once good practice. Electronics and intriguing programs being opened by the new computing machines, sometimes called "thinking machines," and the present indicated new ways and means to use atomic energy far beyond the combustion uses with which we are now familiar are aweinspiring in their prophesy for new fields of endeavor.

If engineers must keep pace with an expanding program, is it necessary that the time spent in college be increased, and if so, how shall that time be used? This subject also is one that this article touches only lightly but it is not difficult to suspect that sometime in the not too distant future there will be a stronger trend toward making engineering colleges truly graduate colleges just as are law and medical colleges. Already a few colleges require 5 years of work for a bachelor's degree and a large number of colleges are introducing expanding graduate work in engineering. The apparent advantages of much that has been done in this direction are not altogether real advantages because so many graduate curricula do not increase the analytical power of young engineers but serve only to delay their entrance into industry.

Unfortunately, not all colleges that are trying to carry on graduate work are properly financed or staffed for that work, and indeed some of them that are properly financed and provided with large faculties have very doubtful ideas as to what should constitute graduate engineering work. Undergraduate curricula are carefully inspected and accredited by Engineers' Council for Professional Development (ECPD), but no plan for graduate curricula accrediting seems feasible. These inspections have been of great value in improving engineering education. A set of standard engineering curricula common to engineering colleges is highly undesirable but even ECPD reports show that in some cases too much emphasis is placed upon conforming to certain curricula patterns, some of which differ too little from the technical institute curricula of today rather than being examples of a scientific standard which should mark and motivate professional engineering. This situation is not an illogical one because many technical institutes now give courses which equal engineering courses of 40 years ago, and indeed often equal some present college curricula. The great demand for engineers almost up to the time of World War II was for operating and construction engineers rather than for analytical engineers able to solve the expanding and increasingly complex problems, examples of which are those presented by our great power networks, the aircraft industry, to say nothing of guided missiles, atomic fission, and so forth. Fortunately, many engineering colleges are meeting today's challenge but there are some that still do not have a proper vision of modern and future engineering. There are still some engineering colleges content with no mathematics for engineers beyond the old type of sophomore integral calculus given in the manner in vogue a generation back. Faculties with such limited vision are inclined to think that graduate work in engineering means simply an expansion of the undergraduate pattern which has prevailed for $3 / 4$ of a century; namely, a pattern based on training men for the routine methods of American operation and mass production.

The great pioneer astronomer, the late Dr. George E. Hale, had the true vision of the education needed by scientists and engineers. He had his vision reduced to operation when he accepted membership on the Board of Trustees of Throop Polytechnic Institute in 1908. He initiated what has become the California Institute of Technology pattern of technical education. That program calls for closely related undergraduate and graduate curricula in a college as far as possible free from the ills caused by sharp departmental lines. Its engineering curricula all include a large measure of scientific courses, presenting as much as possible a work aspect that tends to develop research and analytical skill rather than a knowledge of how to apply standard engineering handbook practice. He also prescribed a deviation from the then standard engineering curricula by insisting that $1 / 5$ to $1 / 4$ of all undergraduate curricula be allotted to humanistic studies. This does not mean that the older types of curricula are wholly unsuitable for the training of engineers. They have a place but they cannot long continue to produce highly qualified professional engineers. Engineers who wish to see the professional engineers' status keep pace with the art and science of engineering must exert every effort to see that graduate college programs provide the type of training that enables graduate engineers to be well acquainted with phases of chemistry, mathematics, and physics not taught in undergraduate courses. Engineers must also urge industry more widely to provide the young engineers in its employ with postcollege training courses that will develop men who can think clearly in a realm of the advanced sciences broader than those of their own particular industry.

\section{PROFESSIONAL STANDARDS}

$\mathrm{W}$ E ARE FACING a particular hazard at this time with regard to the maintenance of high professional standards: the demand for engineers which greatly exceeds supply. The consequent recruiting of men trained at a lower level to do specific engineering or limited technical jobs under the title of engineer will cause many men with good knowledge in some very limited engineering field to think they are professional engineers and entitled to registration, whereas, actually, only a few men who have had such limited experience will have both the ability and fortitude to become engineers by the difficult route of self-study. Indeed, Boards of Registration have already had considerable difficulty of this type, largely with state agencies that operate under the ruling that only registered engineers may get salary increases or promotions. This ruling at first glance seems sound but for many individuals it becomes a serious matter because the men involved, though classified as engineers, are not engineers nor are they doing engineering work. The true situation is that capable men should be given titles describing the work they actually do rather than being classified as engineers. One should think improper titles could readily be changed but there is the rub: the persons operating the agencies in question do not want the titles changed; they want the 
Boards to find some dodge for registering the individuals involved as professional engineers. Thus, we find a few state agencies that shout loudly for high-quality work and advocate civil service examinations as a means of getting that quality also working to weaken and in some cases almost trying to tear down present Board standards for registration.

Perhaps the invention pace is about all the human race can stand. While we in no way encourage technocracy, we are decidedly of the opinion that engineers will just now probably do more for mankind by increasing their efforts to make economic and social conditions keep up with the present development pace of engineering and science rather than attempting to increase that pace.

The "Canons of Ethics for Engineers," published by the ECPD, if thoroughly followed will guarantee a high professional standard. It opens with the Forward:

Honesty, justice, and courtesy form a moral philosophy which, associated with mutual interest among men, constitutes the foundation of ethics. The engineer should recognize such a standard, not in passive observance, but as a set of dynamic principles guiding his conduct and way of life. It is his duty to practice his profession according to these Canons of Ethics.

As the keystone of professional conduct is integrity, the engineer will discharge his duties with fidelity to the public, his employers, and clients, and with fairness and impartiality to all. It is his duty to interest himself in public welfare, and to be ready to apply his special knowledge for the benefit of mankind. He should uphold the honor and dignity of his profession and also avoid association with any enterprise of questionable character. In his dealings with fellow engineers he should be fair and tolerant.

That Forward is followed by 28 sections or paragraphs describing conduct under such headings as "Professional Life," "Relations With the Public," "Relations With Clients and Employees," and "Relations With Engineers."

The first engineer, Imhotep, we claim as such because it was his imagination that designed the Step Pyramid and saw it built 5,000 years ago. Thales, the first recorded electrical engineer, experimented with electricity 2,500 years ago. After a long period of inactivity there were engineers to build the Roman Empire's engineering wonders, and the Renaissance period produced Leonardo da Vinci, whose recently discovered writings describe many engineering conceptions not reduced to practice until centuries later. All of us are familiar with pioneer works associated with such names as Franklin, Faraday, Henry, Maxwell, Ohm, Volta, and Watt, and we pay tribute to men we have seen and heard such as Edison, Steinmetz, Lamme, De Forrest, and a whole multitude of others too numerous to name who have been leaders in the engineering of our day.

Dr. S. Ramo's recent epoch-making address entitled "Synthetic Intelligence," described to us so well the possibilities of super-computers-devices that make the slide rules and the calculating machines used so much during the first half of this century appear extremely simple and inadequate. Some writers have called these super-computers "mechanical brains" and conveyed the idea that they will do all of man's thinking. They are, however, only mental levers, or, in electrical terms, amplifiers for man's thinking. They cannot originate thoughts, they can only increase the speed and power of his thinking even as mechanical levers have changed hand production to production-line production and multiplied in other ways the muscular functioning of men. The best of the computing machines that have so far been conceived or even dreamed of cannot create or formulate the problems to be solved but must have those problems fed into them by master minds that know how to state problems properly and substitute electrical quantities for mechanical entities. As we ponder these thoughts we may well say there is no shortage of goals at which engineers may aim.

The engineer's lack of general culture was a fair complaint two score years ago but by and large there has been a definite improvement in the interest engineers have in being men of culture as well as men of technical ability. Indeed, this very interest is germinating an idea that science and engineering studies, though different from the study of Latin and Greek, may go far toward producing men of recognized culture. Probably most engineers will agree that excessive interest in techniques has caused them to neglect nontechnical community welfare problems.

\section{THE ENGINEER'S RESPONSIBILITY}

Fngineers have a great responsibility which they E probably have not fully realized. No other education or practice equals the study of science and engineering for teaching absolute honesty. Every scientist and engineer knows there can be no deviation from truth in the operation of nature's laws. They have impressed upon them throughout their entire careers the fact that mathematics and scientific data permit no statements that cannot be checked. These lessons, which are basic to a high level of living for individuals, communities, and nations, engineers must, if true to the profession, not only demonstrate by the manner in which they live but they must also enhance their value by applying them through active participation in civic and community affairs.

Participation with many examining boards charged with conducting personal interviews with candidates for positions of great engineering and executive responsibility has given the author great respect for the large proportion of the successful candidates for those positions who are not graduates of engineering colleges and often not graduates of any college. While these men seldom show the full comprehension of the technical work shown by the college graduates, they have enough technical knowledge to do the work and they have learned to know men. That knowledge seems largely to have been acquired by participation in Boy Scouts, YMCA, church, and civic activities. The engineers who have thus combined engineering with other service activities have not only bettered rather directly all of their fellowmen, but have also greatly enriched their own lives.

Engineers at present are held in high repute because they have effectively solved technical defense problems. 
This places them in good positions to be captains as well as crewmen if they are willing to accept captains' responsibilities. Their discoveries of how to make gas turbines, guided missiles, atomic bombs, computing machines, and transistors should produce ways to discover solutions to the larger problem of having people get along better with each other.

Young engineers should be encouraged to increase their scope of activities. More engineers are needed in government-policy-forming and administrative positions. When recognized as professional men, more will be urged to occupy those positions. When urged, they should accept. Memory indicates there are few engineers in Congress, perhaps only three: Congressman Hinshaw and Senators Malone of Nevada and Flanders of Vermont. Flanders in particular is an example to be followed. His record in "Who's Who" shows him as engineer, president of large manufacturing companies, bank director, and the doer of many things that have earned for him the doctorate title and have made him a respected leader in government affairs.

California engineers can immediately help raise the California status by considering the advisability of requiring 8 years' experience rather than 6 for registration. That regulation, without being more severe than the present one, could help the Board a great deal. They can persuade engineers to stop publishing small disagreements with each other, a trait which seems to have grown out of training in precision methods. They can see to it that pressure groups do not weaken the present registration laws. If subelectrical engineers need registration, men who plan wiring and lighting of buildings should function in a way similar to that applied to land surveyors in relation to civil engineers.

\section{REFERENCE}

1. The Economic Status of the Engineer, R. W. Sorensen. AIEE Transactions, volume 57, 1938, pages $786-9$.

\title{
Electric Home Appliances_-100 Years
}

\author{
FRANK THORNTON, JR. \\ FELLOW AIEE
}

\section{$\mathrm{E}$} LECTRICITY IS truly a servant in the house. It enables the homemaker to perform a multitude of tasks in the care of her home and family that would have needed the help of a corps of human servants in the "good old days." Electricity preserves, prepares, and cooks food and disposes of garbage wastes. It pumps and heats water and washes dishes. It removes dust, dirt, and lint from carpets, upholstery, and draperies. It heats, cools, and ventilates rooms. It washes, wrings, dries, and irons clothes. It tells time, rings door bells, and shaves the master of the house. It reduces drudgery, saves food and other materials, and produces better results.

Believe it or not, 100 years ago some people had begun to dream of the useful tasks that electricity might perform in the home. An inventor in Europe had obtained a patent on an electric toaster in 1850 . It used platinum wire for the heating element. The only source of electric current that he knew was that obtainable from a wet battery. Magnetoelectric machines had been made but used only for a few purposes like arc lamps. Inquisitive

Full text of a paper, "Electric Home Appliances-100 Years," presented as part of the AIEE program at the Centennial of Engineering, Chicago, Ill., September 10-12, 1952.

Frank Thornton, Jr., is a consulting engineer, Pittsburgh, $\mathrm{Pa}$. inventors were busy studying electricity and had begun to suggest all kinds of useful applications.

By 1862 the commutator had been added to the magnetoelectric machine so as to provide direct current which up to that time had been provided only by batteries.

By 1872 this machine had been modified into the type that is the basis of all modern electric generators. Many improvements in arc lights, arc furnaces, and other applications of electric power were made during the previous 10 years.

The decade from 1872 to 1882 saw the birth of the modern electrical age. A practical incandescent lamp was perfected and a system of generating and distributing electric current at a constant voltage to operate a multitude of such lamps in parallel was developed and put into commercial operation.

From 1882 to 1892 progress was rapid. The a-c system of generation, transmission, and distribution was put into practical operation with all the auxiliary equipment needed to regulate and control the flow of energy to lamps, motors, heaters, and other apparatus. Electricity was becoming available over an ever-expanding area. Experimental models of many electrically heated and motor-operated 